Article

\title{
Sustainable Education Using Augmented Reality in Vocational Certification Courses
}

\author{
Chia-Jung Lee (D) and Yen Hsu *(D) \\ The Graduate Institute of Design Science, Tatung University, Taipei 104, Taiwan; d10717011@ms.ttu.edu.tw \\ * Correspondence: yhsu@gm.ttu.edu.tw; Tel.: +886-2-2858-0164
}

\begin{abstract}
In the field of vocational education, no studies have examined the use of augmented reality (AR) learning technologies in the teaching of cosmetology. However, this study proposed the "Makeup AR" learning approach and conducted a quasi-experiment to examine the interaction effect between said approach and students with active and reflective learning styles. The research participants were 70 students from a vocational senior high school. The experimental group comprised 36 participants who were taught using Makeup AR, and the control group comprised 34 participants who were taught using an e-book. The results revealed that the use of Makeup AR improved students' learning effectiveness. The proposed approach also effectively enhanced students' self-efficacy and reduced their cognitive load. The students with a reflective learning style had a higher cognitive load than those with an active learning style when using the e-book learning approach. No difference in learning motivation was noted between the experimental and control groups. Overall, Makeup AR is suitable for makeup design certification courses in vocational senior high schools and can enhance learning effectiveness, improve students' self-efficacy, and reduce cognitive load. This study suggests that the implementation of AR technology in certification courses can be beneficial to learning outcomes.
\end{abstract}

Citation: Lee, C.-J.; Hsu, Y.

Sustainable Education Using Augmented Reality in Vocational Certification Courses. Sustainability 2021, 13, 6434. https://doi.org/ $10.3390 /$ su13116434

Academic Editor: Enrique-Javier Díez-Gutiérrez

Received: 28 April 2021

Accepted: 3 June 2021

Published: 5 June 2021

Publisher's Note: MDPI stays neutral with regard to jurisdictional claims in published maps and institutional affiliations.

Keywords: augmented reality; mobile learning approach; learning technologies; learning effectiveness; learning motivation; self-efficacy; cognitive load

\section{Introduction}

The convenience and effectiveness of using smartphones in learning activities have attracted the attention of educators worldwide [1-4]. Studies have indicated that teacher lecturing is not beneficial for improving students' learning effectiveness and that the use of technology in teaching has considerable benefits over lecturing [5-7]. Researchers are actively attempting to develop new teaching methods that employ smartphone technology to overcome limitations in teaching, with the aim of providing students with new learning experiences and more effective learning methods [8-10]. The prevalence of technology and the continual introduction of new technologies affect the pedagogy. In education, increasing emphasis is placed on the use of technology in learning, and researchers continue to introduce new technological features into learning to improve students' learning effectiveness [11,12].

Mobile learning has developed rapidly and is constantly changing and developing. Technology makes the learning process more compelling, thus enhancing learning efficiency and effectiveness $[13,14]$. Face-to-face class is the primary teaching method that has been used for vocational education, and teacher demonstrations are a fundamental aspect of vocational education. Students consider the teacher's explanation, observe the demonstration of relevant skills, and then learn by imitating techniques and practicing repeatedly; subsequently, the teacher provides immediate feedback and corrections in class $[15,16]$. In the field of technology-related or vocational education, students should take the initiative in academic activities, learn through doing and continual practice, and avoid simply listening to the teacher in the classroom. Students need to learn through hands-on practice 
and continual, repetitive exercises to internalize the skills being learned [17]. Research has indicated that it is necessary to explain the impact of digitalization on vocational education and adopt mobile learning in schools $[18,19]$. Because mobile devices are closely and intricately intertwined in everyday life, they present many opportunities for enhancing the learning experience [20].

Many studies have reported that augmented reality (AR) can improve students' learning effectiveness. Compared with teacher demonstrations, text, and images, AR provides a more vivid, fun, and unique visual learning experience to students [21,22]. The use of mobile devices can benefit student learning and participation $[23,24]$. One study indicated that to improve learning effectiveness, it is necessary to employ learning strategies that incorporate personal learning styles [25].

The present study explored the learning effectiveness, motivation, self-efficacy, and cognitive load of students who used an AR-based learning approach called Makeup AR in a makeup design certification course. The learning materials in Makeup AR were centered on the content of the eyebrow unit of the makeup design certification course. Makeup AR was applied in the course, and the advantages of this AR learning method were analyzed. We assessed the implementation and evaluation of cosmetic design certification courses in vocational training that adopted either the Makeup AR or e-book learning approach. The following four research questions were proposed to guide the study:

(1) Do the Makeup AR and e-book learning approaches affect the learning effectiveness of students with different learning styles?

(2) Do the Makeup AR and e-book learning approaches affect the learning motivation of students with different learning styles?

(3) Do the Makeup AR and e-book learning approaches affect the self-efficacy of students with different learning styles?

(4) Do the Makeup AR and e-book learning approaches affect the cognitive load of students with different learning styles?

\subsection{Teaching in the Makeup Design Certification Course}

In the eyebrow unit of the makeup design course, students initially learn to draw the frame of eyebrows on paper using tools such as rulers and colored pencils; they then draw the lines of eyebrows in the frame. Students then transfer their paper-based skills to actual faces. In conventional teaching, students are typically passive learners, meaning they receive knowledge and skills taught by teachers [26]. However, without the presence of teachers when practicing, beginners cannot know whether they have correctly drawn eyebrows, and teachers' subjective sense of aesthetics when evaluating their work makes it difficult for students to understand their mistakes in a precise and scientific manner; these factors can lead to frustration among students during learning. Moreover, makeup practice on paper considerably differs from the actual application of makeup on a three-dimensional (3D) face. The relative positions of face parts differ among individuals; therefore, drawing eyebrows on paper, representing the standardized relative positions of parts of the face, might be inapplicable to the relative 3D position of face parts, since they are unique to each person. Hence, beginners might encounter difficulty in drawing eyebrows on a face. Furthermore, students tend to feel anxious when facing an unfamiliar model, making it even more challenging for them to draw bilaterally symmetrical and balanced eyebrows.

Makeup design is the foundation of the department of cosmetology skills and is thus a mandatory course specified in the curriculum guidelines of makeup design certification courses in vocational senior high schools. The makeup design certification course is divided into seven units covered during the semester: foundation, blush, eyebrows, eye shadow, eyeliner, nose, and lips. Relevant studies have revealed that the eyebrows are a prominent feature of the face; specifically, they play an essential auxiliary role in expression, communication, and first impressions. Moreover, eyebrows are crucial for communicating one's will, personality, and feelings [27-30]. Each person's facial contours and features differ depending on the visual effects created by their eyebrows' shape, length, thickness, 
and color. The extent to which the arch and color of eyebrows look natural determines an individual's style. Makeup can cover and balance defects, generate different visual effects, energize the eyes, make the nose look taller, and increase an individual's attractiveness, beauty, confidence, and style. Thus, learning to manipulate these elements is critical in cosmetology [31-34].

Several difficulties are typically encountered during the teaching of a makeup design course. In the conventional teaching method, students follow the teacher's demonstration and use their imagination to place a baseline on the face of the person receiving the makeup application. As mentioned previously, beginners commonly feel anxious when applying makeup on an unfamiliar model. Through Makeup AR, beginners can draw a virtual line on the face; this may solve the difficulty of imagining the baseline, enabling students to improve their learning efficiency and to know the precise position on the face at which to apply the makeup [35-37]. Among the many eyebrow styles introduced in the eyebrow unit, students begin by drawing the most standard eyebrow shape based on the eyebrow position relative to other face parts. Therefore, this study used Makeup AR for makeup design with a focus on the standard eyebrow shape. To assist in makeup design learning, Makeup AR was set according to the standard eyebrow positions in the literature and adjusted to fit the eyebrow positions and facial features of the Asian population. Students gained experience and skills in eyebrow makeup design through learning and hands-on activities.

\section{2. $A R$}

AR technology superimposes virtual information into real spaces through a screen [38]. AR involves a combination of camera recognition technology and computer operations. When a preset image or sensing medium appears on the camera screen, the virtual object defined by an image or a symbol is superimposed onto the natural environment, and the presentation of the virtual object changes depending on the user's viewing angle and distance to create a visual experience comparable to that of viewing a real object [39]. In virtual reality, users enter an artificial environment and cannot see the natural world around them. By contrast, AR superimposes or combines virtual information into realworld settings, enabling users to still see the real world. Therefore, AR is not a substitute for reality but rather supplements the perceptions of and interactions with the real world, provides virtual information to complement insufficient real-world information, and creates an environment where virtual reality and reality coexist. An AR display should include three major characteristics: a combination of natural and virtual environments, real-time interaction, and 3D presentation [38].

Milgram et al. were the first to propose the concept of AR. AR is located between the real and virtual environments (if presented as a continuum) but is closer to the natural environment; augmented virtuality is closer to the virtual environment, and at the midpoint of the spectrum is mixed reality (Figure 1). Therefore, AR refers to the addition of elements of the virtual environment to a natural environment [39]. Azuma noted that a user's senses are still grounded in the natural environment when engaging in AR, and virtual elements are added to the natural environment to facilitate the coexistence of real and virtual elements in the same space [38]. Technological development has prompted the emergence of new teaching methods. Technology can play an essential role in the teaching process and can enhance learning effectiveness and efficiency $[40,41]$.

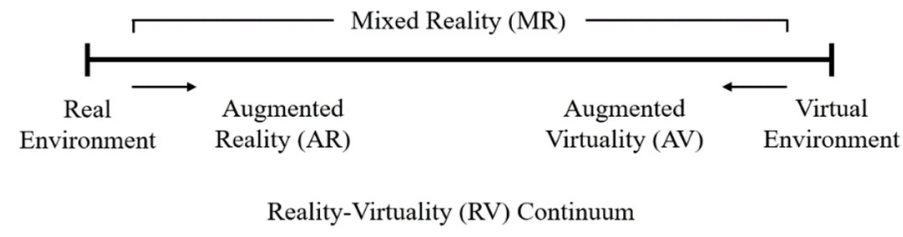

Figure 1. Relationship between augmented reality, augmented virtuality, and mixed reality. 
In addition, AR can be widely applied in daily life, including in games, medical treatment, navigation, social interaction, and education [14]. According to Akçayır and Akçayır [42], AR is widely used in education and has become a popular research topic. Technology makes the learning process more compelling. The combination of AR and education enables students to become immersed in the learning experience $[14,42]$. AR can be applied to foreign languages [43,44] and arts [41]. The educational value of AR applications in the field of design education has increased considerably. Di Serio, Ibáñez, and Kloos studied visual art students' use of an AR-based guided tour for artwork learning; their results revealed that compared with conventional slide-based teaching, the AR method resulted in higher learning concentration and motivation among students [41,45]. AR applications can be crucial learning tools in clothing design courses to cultivate clothing design skills [16]. Applying AR in a sewing course improved students' learning experience and ability to manage complex problems [22]; the results revealed more satisfactory learning outcomes from using AR compared with conventional methods. In addition to applying AR in design education, researchers have integrated it into learning activities in other education fields [46,47]. However, related studies have not discussed the application of AR in a makeup design course.

AR in experiential learning facilitates interaction between students and learning materials; while participating in virtual operations, students are connected with the natural environment to improve their spatial skills [48]. AR improves not only the sensory experience but also students' learning effectiveness [49]. A study revealed that AR applied in education generally makes the learning process more stimulating and improves learning efficiency [14]. Hence, AR applications in education have demonstrated considerable potential and advantages $[14,50]$. The aforementioned studies have highlighted the application of AR in courses in various educational fields. AR has been proven to enhance students' awareness of the natural environment, support teaching and learning in the educational environment, and improve students' learning motivation and interest [51]. However, related studies have not discussed the application of AR in a makeup design course. The current study addresses this gap in the literature.

Many studies have indicated that it is helpful to consider learning styles in pedagogical research [52-54]. The most frequently discussed learning paradigm is the active versus reflective learning style dimension proposed by Felder and Silverman [55]. Learning styles have been widely used to discuss the development of AR learning systems for technologyassisted learning [56-58]. Hawk and Shah reported that, assuming each student has a different learning style, course content and teaching methods should be tailored to meet their varying needs [59]. In the active/reflective learning style dimension proposed by Felder and Silverman, "active" refers to a preference for practical exploration, trial, and active interaction with things to learn, and "reflection" refers to a preference for thinking profoundly and passively receiving information. Therefore, this study explored the effects of different learning strategies on students' learning effects, incorporating material designed to appeal to students with active and reflective learning styles.

Many studies have indicated that learning through AR can improve self-efficacy, thus reducing students' cognitive load. Self-efficacy beliefs are defined as "people's judgment[s] of their capabilities to organize and execute courses of action required to attain designated types of performances". Self-efficacy belief refers to an individual's perceptual ability to learn or complete a specified action [60]. It is a form of self-evaluation that influences individuals' decisions, efforts, and mastery of behaviors [61]. This perceptual ability refers to students' belief that they possess adequate ability to complete a learning activity [62].

Moreover, cognitive load theory provides guidelines for presenting information in a manner that encourages learner activities that optimize academic performance. This theory refers to the load placed on an individual's cognitive system when the individual is engaged in a specific job, including "mental load" and "mental efforts". Mental load refers to the load of course learning tasks or the environment on students, whereas mental effort refers to the total load on students when performing course learning tasks [63]. The 
present study evaluated the Makeup AR and e-book learning approaches in a vocational cosmetic design certification course.

\section{Materials and Methods}

\subsection{Research Tools}

The measurement tools included a pretest, a posttest for examining learning effectiveness, and a survey for evaluating learning motivation, self-efficacy, and cognitive load. The pretest determined students' prior knowledge regarding the eyebrow makeup topics included in this study, and the posttest evaluated students' learning effectiveness after the experiment. The pretest was composed of 25 four-option multiple-choice questions; students were required to select one correct answer for each question, with a score of 100 points per test. The posttest consisted of 20 multiple-choice items, with a score of 3 points per item, and two short answer questions, with 20 points per question; the posttest score was 100. All the tests were selected by three teachers with more than 9 years of experience in teaching the makeup certification course and were subsequently reviewed by experts from the Skill Evaluation Center of Workforce Development Agency, MOL.

This study selected the active and reflective learning dimensions and the items most suitable for this research from among the eight learning style categories of the Index of Learning Styles. Said index is used to investigate the different learning styles of students [64]. The learning motivation scale was modified according to the questionnaire developed by previous researchers [57]. This questionnaire consisted of seven items (e.g., "Studying cosmetics skills is worthwhile in the makeup course" and "I will actively seek more information to learn about makeup courses"); all items were rated on a 5-point rating scale. The Cronbach's alpha value of the questionnaire was 0.79 , indicating acceptable internal consistency and reliability. The self-efficacy questionnaire was modified based on the measurement questions published by Wang and Hwang [65]. This questionnaire consisted of eight items that were rated on a 5-point Likert scale. The Cronbach's alpha value of the questionnaire was 0.92 [65]. The cognitive load questionnaire was modified from that developed by Hwang et al.; it consisted of two dimensions with a total of eight items. The Cronbach's alpha value of the questionnaire was 0.96 [66].

\subsection{Experimental Design}

\subsubsection{Participants}

The participants in this study were first-year students at a vocational senior high school who had not studied makeup previously. Seventy volunteers were recruited and randomly assigned to the experimental group $(n=36)$ or the control group $(n=34)$.

\subsubsection{Experimental Procedure}

The same teacher instructed both groups to eliminate the confounding effect of different teaching styles and experiment results [67]. The teacher in charge was a senior makeup teacher with 10 years of teaching experience, and the research focus was makeup teaching. The teacher was responsible for organizing the teaching content and implementing the current experiment. To ensure the accuracy of the experiment, volunteers were unaware of their group assignment and the existence of another group.

The experimental procedure is illustrated in Figure 2. Before the learning activities, students opted for the 40-min makeup certification design course: eyebrow unit. Students practiced drawing proper eyebrows on paper. Then, a pretest was conducted for $10 \mathrm{~min}$ to determine their baseline ability for the makeup certification design course. Later, students in the experimental group were asked to use Makeup AR to transfer their paper-based eyebrow skills to actual faces. When students in the experimental group pointed their smartphone at a face with the Makeup AR app open, this activated the AR auxiliary effect of eyebrow makeup, and auxiliary lines were displayed on the screen (Figure 3). The correct position of the eyebrows was thus provided on the screen. The students then drew eyebrows according to the AR display on the screen (Figure 4). The app recommended an 
appropriate eyebrow type based on the face shape. Students acquired eyebrow makeup knowledge through matching suggestions (Figure 5).

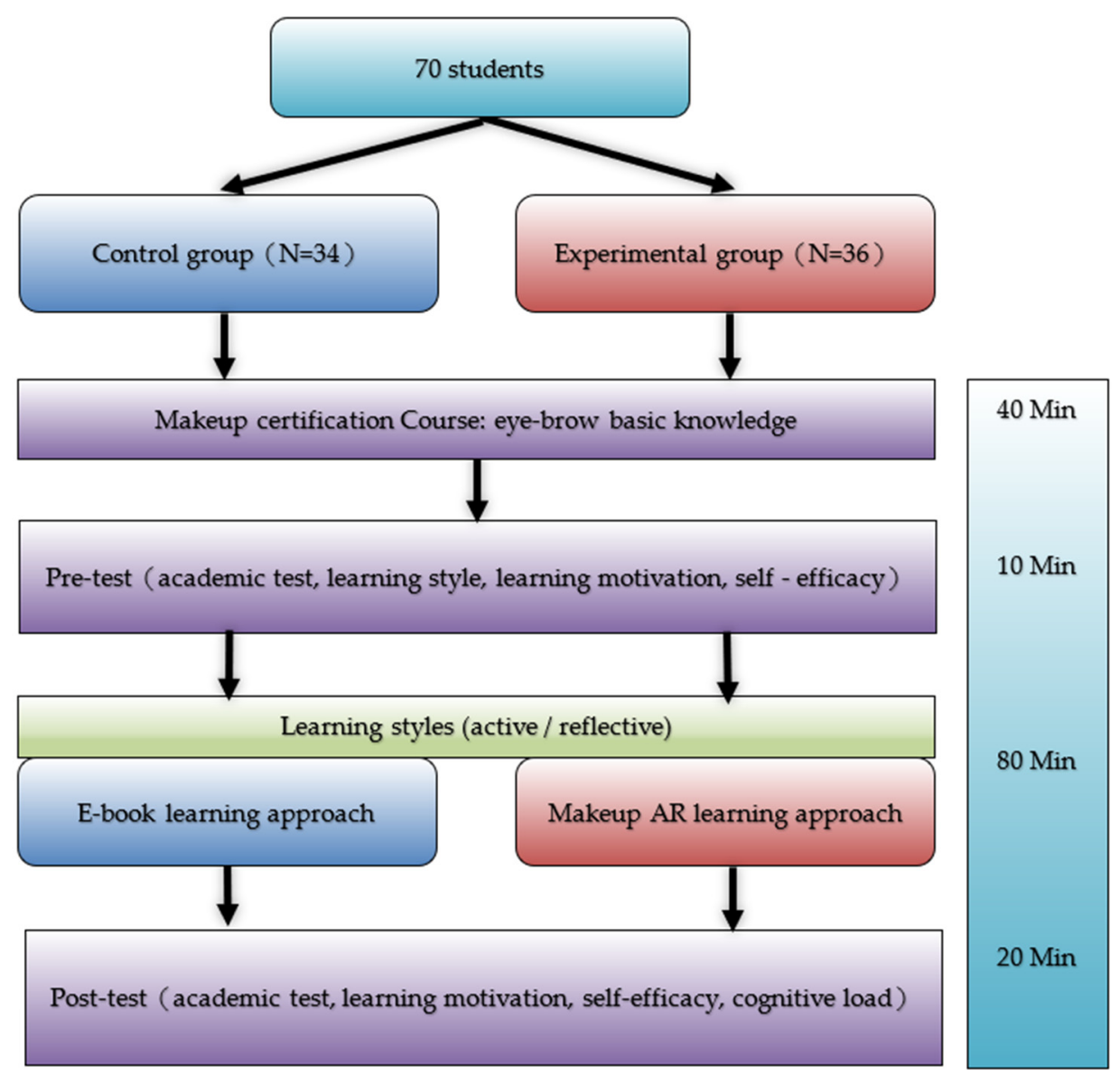

Figure 2. The experimental process.
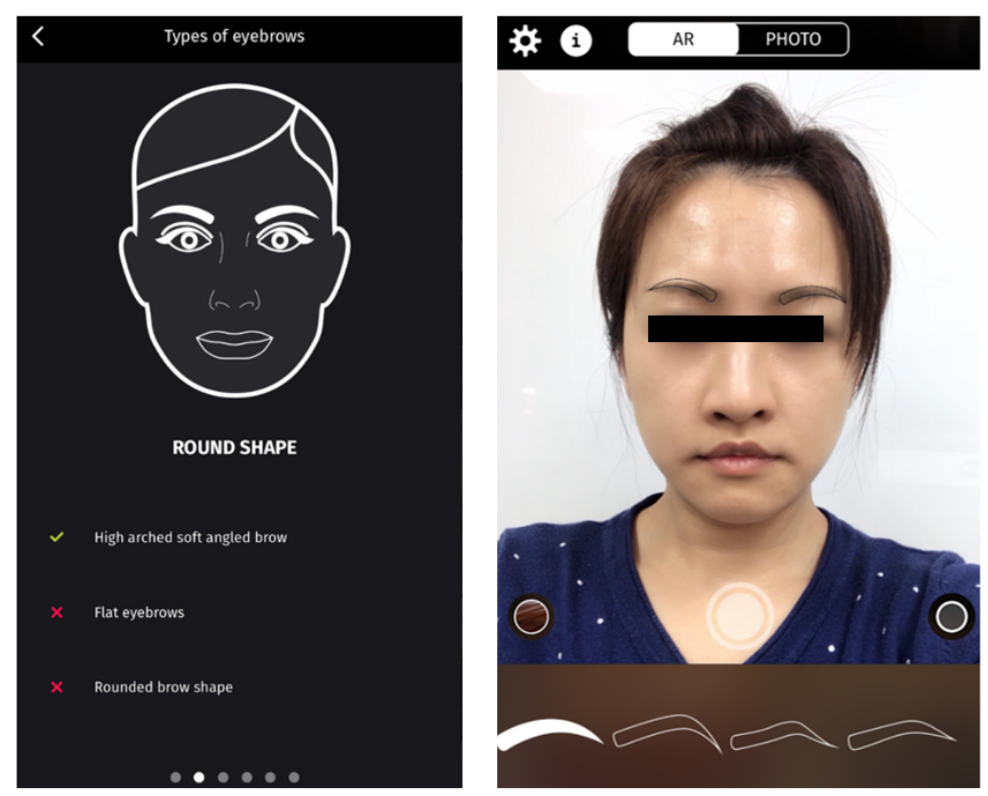

Figure 3. Eyebrow makeup information superimposed by Makeup AR.

Students in the control group imitated the makeup content in an e-book to learn to draw eyebrows. Finally, a 20-min academic posttest on eyebrow makeup and learning 
motivation and self-efficacy and a cognitive load survey were implemented to measure students' learning effectiveness. Three experts selected the Makeup AR and e-book that were most suitable for beginners.
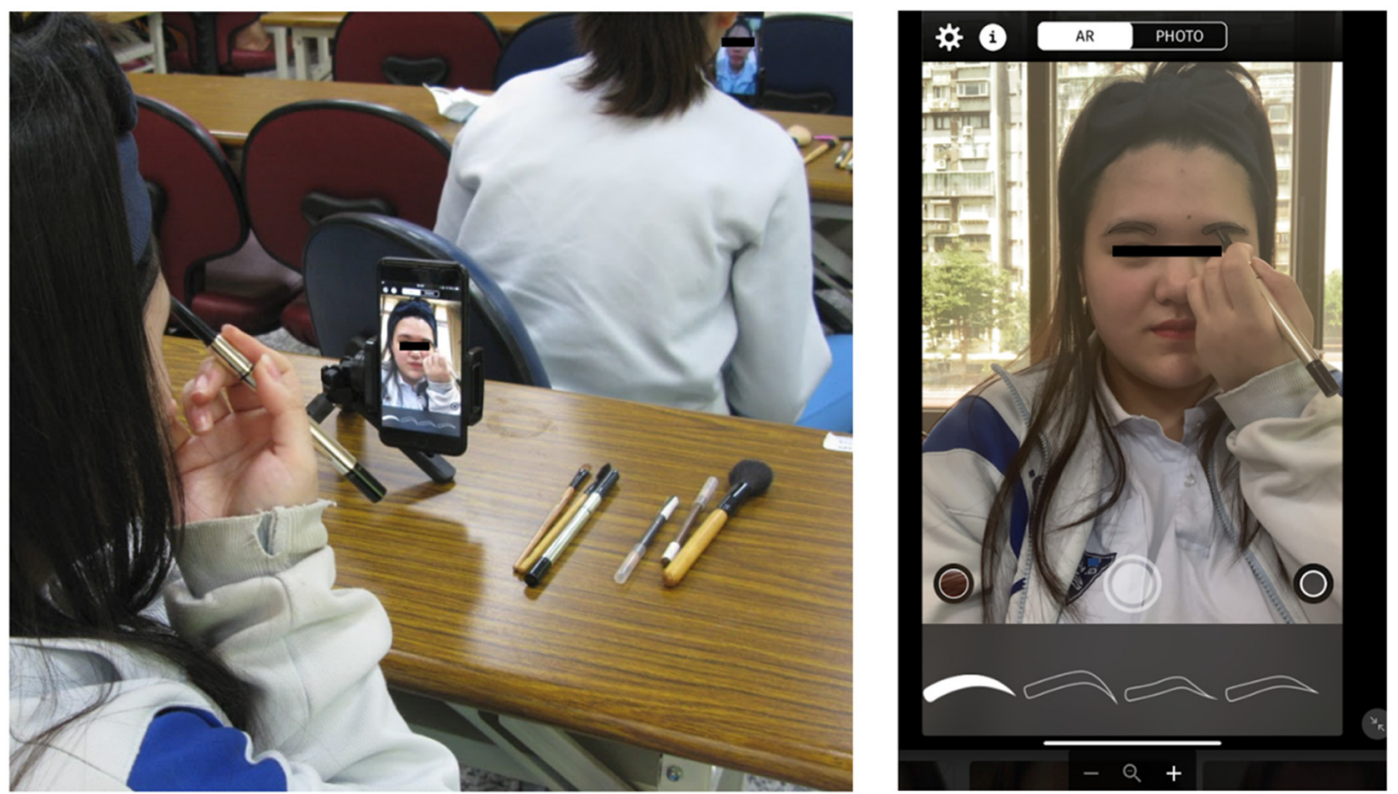

Figure 4. Use status of experimental group students.
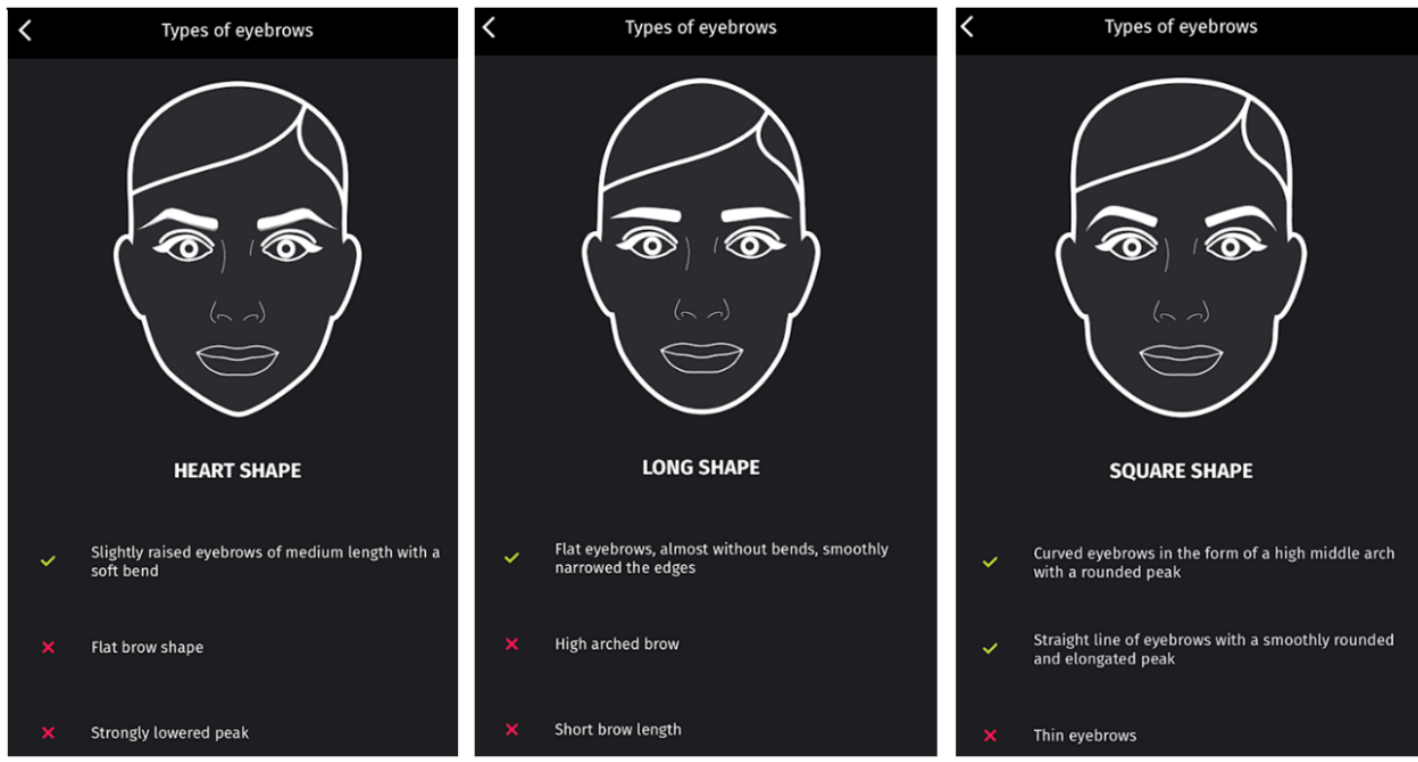

Figure 5. Matching suggestions for eyebrow types and face shapes.

\section{Results}

\subsection{Learning Effectiveness}

In recent years, many researchers have actively explored learning styles. Employing learning methods or providing learning content that suit students' learning styles can enhance the effectiveness of education to a considerable extent [68]. Therefore, this study investigated the impact of using the Makeup AR and e-book learning approaches on the performance of students with different learning styles. First, according to the study style questionnaire, students were divided into two types: active and reflective.

For students' learning effectiveness, a two-way analysis of covariance (ANCOVA) was used to analyze students' results using different learning approaches, namely Makeup AR 
and the e-book. Active and reflective learning styles were the independent variables, the posttest questionnaire ratings of learning effectiveness were the dependent variable, and the pretest questionnaire ratings of learning effectiveness were covariates.

After verifying that the assumption of the homogeneity of regression was not violated $(F=0.465, p>0.05)$, the posttest scores of the four groups were analyzed using a twoway ANCOVA. As presented in Table 1, the interaction between the dependent variables exerted a significant effect $\left(F=7.318, p<0.05, \eta^{2}=0.101\right)$ on students' learning effectiveness, implying that a simple main-effects analysis was required to explore the effects of learning approaches.

Table 1. Results of two-way ANCOVA on students' learning effectiveness.

\begin{tabular}{ccccccc}
\hline Factors & SS & df & MS & $\boldsymbol{F}$ & Sig & $\boldsymbol{\eta}^{2}$ \\
\hline Learning approach & 1043.892 & 1 & 1043.892 & $7.318^{*}$ & 0.009 & 0.101 \\
Learning style & 98.783 & 1 & 98.783 & 0.692 & 0.408 & 0.011 \\
Learning approach * & 18.503 & 1 & 18.503 & 0.130 & 0.720 & 0.002 \\
$\quad$ Learning style & & & & & &
\end{tabular}

Table 2 presents descriptive data of the two groups of students' posttest learning effectiveness scores. Students who learned using different learning approaches exhibited significantly different levels of learning effectiveness $\left(F=7.318, p<0.05, \eta^{2}=0.101\right)$. Makeup AR exerted significantly stronger positive effects (adjusted mean $=85.193, \mathrm{SE}=2.008$ ) on students' learning effectiveness than the e-book learning approach did (adjusted mean $=77.351, \mathrm{SE}=2.084$ ).

Table 2. Descriptive data of the learning achievements.

\begin{tabular}{ccccccc}
\hline Learning Approach & $\mathbf{N}$ & $\mathbf{M}$ & SD & Adjusted Mean & SE & $\eta^{\mathbf{2}}$ \\
\hline Experimental Group & 36 & 85.00 & 11.17 & 85.193 & 2.008 & 0.101 \\
Control Group & 34 & 77.94 & 13.17 & 77.351 & 2.084 & \\
\hline
\end{tabular}

Different learning styles had no significant effect on learning effectiveness $(F=0.692$, $\left.p>0.05, \eta^{2}=0.011\right)$. The students in the experimental group performed better in the posttest than the students in the control group, who performed poorly in the posttest due to reduced knowledge retention. Hence, if appropriate scientific and technological teaching aids are used in regular learning activities to strengthen students' learning and thinking, satisfactory results can be achieved in terms of knowledge acquisition.

\subsection{Learning Motivation}

Two-way ANCOVA was used to analyze learning motivation. The results are presented in Table 3. The two-way ANCOVA indicated that the influence of the interaction between learning approaches and learning styles was nonsignificant $(F=0.076, p>0.05)$, as displayed in Table 3. The different learning approaches of the two groups of students had no significant influence on learning motivation $\left(F=0.247, p>0.05, \eta^{2}=0.004\right)$ after excluding pretest questionnaire ratings. There was no significance in learning styles. Furthermore, the adjusted means of the Makeup AR learning group and the e-book learning group were 3.93 (standard deviation $[S D]=0.58)$ and $4.08(\mathrm{SD}=0.55)$, respectively. Hence, no significant difference was observed in motivation between the groups who learned with the Makeup AR and e-book learning approaches. 
Table 3. Results of the two-way ANCOVA on students' learning motivation.

\begin{tabular}{ccccccc}
\hline Factors & SS & df & MS & $\boldsymbol{F}$ & Sig & $\boldsymbol{\eta}^{2}$ \\
\hline Learning approach & 0.083 & 1 & 0.083 & 0.247 & 0.621 & 0.004 \\
$\quad$ Learning style & 0.259 & 1 & 0.259 & 0.775 & 0.383 & 0.014 \\
Learning approach * & 0.025 & 1 & 0.025 & 0.076 & 0.784 & 0.001 \\
$\quad$ Learning style & & & & & &
\end{tabular}

\subsection{Self-Efficacy}

Two-way ANCOVA was used to analyze self-efficacy. The results are displayed in Table 4. The two-way ANCOVA indicated that the effect of self-efficacy on the interaction between learning approaches and learning styles was nonsignificant $(F=0.010, p>0.05)$. A significant effect of self-efficacy on the posttest questionnaire ratings of students who learned using the two approaches $\left(F=5.558, p<0.05, \eta^{2}=0.092\right)$ was noted after the exclusion of prequestionnaire ratings, whereas no significant difference was observed on the ratings of students who learned using different learning styles $(F=2.063, p>0.05$, $\eta^{2}=0.036$ ). Furthermore, the adjusted means of the Makeup AR and e-book learning approaches were $3.90(\mathrm{SD}=0.88)$ and $3.42(\mathrm{SD}=0.67)$, respectively. This finding implies that the Makeup AR learning approach could improve students' self-efficacy more than the e-book learning approach.

Table 4. Results of two-way ANCOVA on students' self-efficacy.

\begin{tabular}{ccccccc}
\hline Factors & SS & df & MS & $\boldsymbol{F}$ & Sig & $\boldsymbol{\eta}^{\mathbf{2}}$ \\
\hline Learning approach & 3.474 & 1 & 3.474 & $5.558^{*}$ & 0.022 & 0.092 \\
$\quad$ Learning style & 1.290 & 1 & 1.290 & 2.063 & 0.157 & 0.036 \\
Learning approach * & 0.006 & 1 & 0.006 & 0.010 & 0.921 & 0.000 \\
$\quad$ Learning style & & & & & &
\end{tabular}

\subsection{Cognitive Load}

Two-way ANOVA was used to analyze cognitive load. The results are presented in Table 5. A significant effect was found between learning approaches and learning styles $(F=5.391, p<0.05)$. In addition, a significant effect was noted for learning approaches $\left(F=9.728, p<0.05, \eta^{2}=0.148\right)$. Learning styles $\left(F=1.309, p>0.05, \eta^{2}=0.023\right)$ did not exert a significant effect on students' cognitive load when using the system.

The mean values of students' cognitive load degree scores were $2.24(\mathrm{SD}=0.16)$ for the Makeup AR learning group and $2.95(\mathrm{SD}=0.16)$ for the e-book learning group. This finding implies that Makeup AR reduced students' cognitive load resulting from participating in the learning activity. By contrast, the mean values of cognitive load ratings were 2.46 $(\mathrm{SD}=0.14)$ for students with an active learning style and $2.72(\mathrm{SD}=0.17)$ for students with a reflective learning style, implying that students with a reflective learning style had a higher cognitive load than those with an active learning style (Figure 6).

Table 5. Results of two-way ANOVA on students' cognitive load.

\begin{tabular}{ccccccc}
\hline Factors & SS & df & MS & $\boldsymbol{F}$ & Sig & $\boldsymbol{\eta}^{2}$ \\
\hline Learning approach & 7.329 & 1 & 7.329 & $9.728 *$ & 0.003 & 0.148 \\
$\quad$ Learning style & 0.986 & 1 & 0.986 & 1.309 & 0.257 & 0.023 \\
$\begin{array}{c}\text { Learning approach * } \\
\text { Learning style }\end{array}$ & 4.062 & 1 & 4.062 & $5.391 *$ & 0.024 & 0.088 \\
${ }^{* p<0.05 .}$ & & & & & &
\end{tabular}




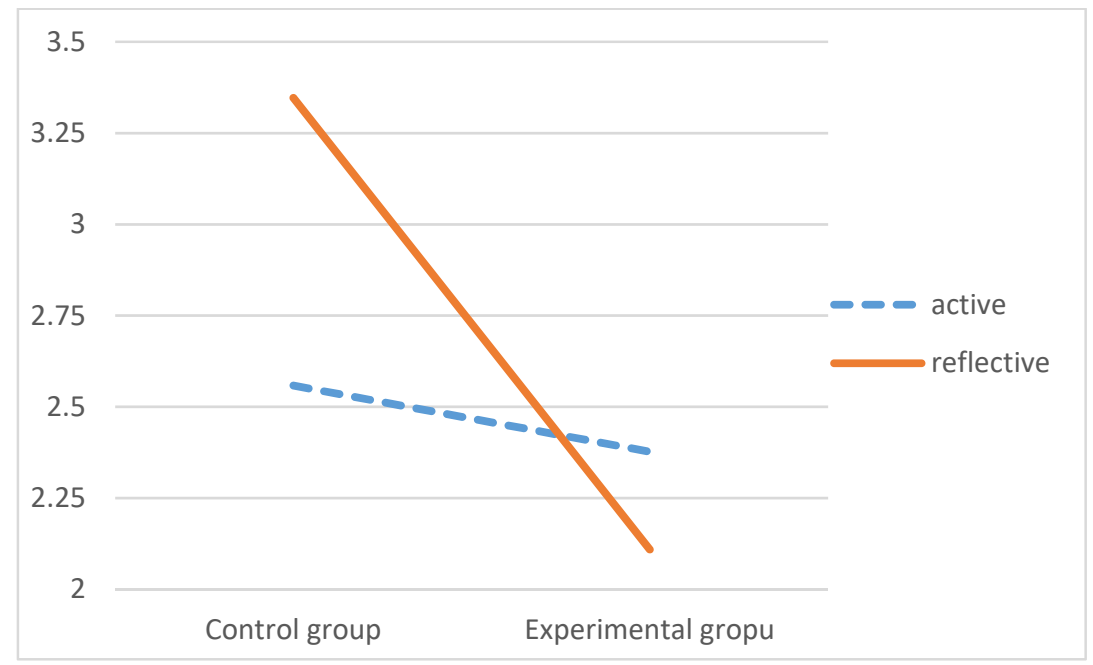

Figure 6. Estimated marginal means for intrinsic cognitive load.

\section{Discussion}

This study used Makeup AR for teaching activities and analyzed its effectiveness for improving learning outcomes. AR technology was thus introduced into the makeup design certification course to bring a new experience to makeup education and promote AR teaching methods in cosmetics skills education. Because learning styles play a crucial role in the learning process, this study explored the active and reflective learning styles and introduced two different learning approaches to determine learning effectiveness, self-efficacy, cognitive load, and learning motivation. The experiment results revealed that the proposed approach significantly improved students' learning effectiveness and self-efficacy while reducing their cognitive load. However, no significant effect was noted for learning motivation.

Regarding learning effectiveness, that of the Makeup AR approach was higher than that of the e-book approach. The experiment results verified the effectiveness of the Makeup AR learning approach. Compared with the e-book group, the experimental group achieved higher scores and demonstrated greater learning effectiveness. This finding indicates that Makeup AR would be beneficial for the makeup certification course. Students can learn makeup better in a learning-by-doing environment through Makeup AR and hands-on operations in the makeup skills course. Related research mentions that situated learning (SL) is a crucial element that affects AR learning, and it is necessary to consider situated learning (SL) in learning activities [69-71].

Regarding self-efficacy, the analysis results indicated that the interactive effect of the learning approach and learning style did not reach a significant level; the main effects of learning approach reached a significant level, whereas those of learning style did not. The experiment results verified the positive effect on self-efficacy from the Makeup AR learning approach. Compared with the e-book group, the experimental group achieved higher scores and demonstrated greater self-efficacy. With the eyebrow lines displayed on the smartphone screen, students can learn the correct eyebrow position more quickly and clearly, significantly increasing their self-efficacy in learning. In terms of learning style, whether active or reflective, the self-efficacy of using Makeup AR is higher than that of the e-book. From the results, it can be inferred that, whether for active or reflective students, Makeup AR can improve students' confidence in completing tasks and achieving goals during the learning process. Compared with e-books, students can improve their confidence in learning tasks, believing that they can achieve goals. At the same time, it also echoes the relevant research pointing out that learning activities incorporating AR technology in the classroom can help students with higher self-efficacy learn more concepts and knowledge [72]. 
Regarding cognitive load, the results revealed that the interactive effect of the learning approach and learning style was significant; the main effect of the learning approach reached a significant level, whereas the main effect of the learning style did not. Hence, the cognitive load of Makeup AR was lower compared with the e-book learning approach for both active and reflective learners. The Makeup AR learning approach can reduce pressure and the burden in the learning process for both active and reflective learners. These findings indicate that providing active learners with personally operated, experiential, and interactive learning can help reduce their cognitive load. However, for reflective learners, because of their habit of thinking, working, and learning alone, a learning environment that provides an e-book learning approach may be sufficient. Makeup AR could reduce students' cognitive load because it makes them participants in the learning activity. From the perspective of learning style, for reflective students, the cognitive load of Makeup AR is lower than that of "active" students, and the cognitive load of the e-book is higher than that of active students. Reflective students have independent repetitive thinking and independent work learning methods for new information habits, so Makeup AR has independently operable learning characteristics, which can meet the learning mode of reflective students, so cognitive load is lower than that of active learning. Regardless of whether it is for active or reflective students, the cognitive load of imported "Makeup AR" is lower than that of "e-book". From the results, it can be inferred that whether it is for active or reflective students, Makeup AR can reduce the pressure and burden of students in the learning process. Compared with the e-book, students can integrate into the situation, focus on important information, and avoid distractions. At the same time, it also echoes what Salen mentioned: if students are taught enough in science and technology, they will not feel frustrated because of failure or give up because of too much cognitive load. They can gain more knowledge and reduce tasks and information [73].

Finally, regarding learning motivation, the experiment results indicated that the interactive effect of learning approach and learning style was nonsignificant; the main effect of learning approach was nonsignificant, as was the main effect of learning style. In the learning style of active or reflective students, using Makeup AR and e-book has good learning motivation. From the results, it can be inferred that whether it is for active or reflective students, Makeup AR can improve students' expectations of what they have learned during the learning process. Students are willing to spend time and energy on the study of makeup actively. Both groups of students were exposed to these learning systems for the first time; thus, improving students' learning motivation through an 80-min study may be challenging, because when students use emerging technology, they also face many uncertainties [69]. Therefore, it may take more time to cultivate their learning motivation. Huang et al. and Yang et al. have reported that a short study period may not be sufficient for improving students' learning motivation and that students need more time and learning experience to develop their abilities [74,75]. It may also be due to the difficulty, change, and flexibility of the makeup certification course itself and because students are under pressure to obtain certificates. Most students believe that learning the contents of the makeup design certification course thoroughly is challenging.

In addition to conveying knowledge, a makeup certification course must also include technical makeup skills. This study differed from previous research on AR learning applications, because most previous studies have focused on learning in language or formal courses. However, techniques and skills are also vital points on the makeup certification exam. The results of this study provide empirical outcomes; however, a partial conflict also exists. Another possible reason is for these first-year high school students who have never learned makeup. No matter what method is used to learn eyebrow makeup, it is full of positive learning motivation. Using makeup AR or the e-book makes it impossible to highlight which method has better learning motivation results. In the future, more students participating in the experiment may be able to increase the sample data, and there may be different analysis results. 


\section{Conclusions}

The contribution of this study is that, unlike previous studies on AR learning, Makeup AR, which is easy to operate and convenient, was studied. This study used the Makeup AR learning approach to assist the teaching and learning of the makeup design certification course. Although students, especially beginners, had some difficulties using Makeup AR, these were easily overcome. For beginners, switching from eyebrow makeup practice on paper to a 3D face may represent a considerable challenge, because they must overcome the differences between flat paper and a 3D face. With the aid of AR, a smartphone screen can provide auxiliary lines for eyebrow makeup, helping students to draw eyebrows quickly in precise positions. Related research pointed out that AR applications can be located in any educational environment; they can be added to situated learning (SL) to make AR have more specific effects [69], which is the most commonly used method in AR teaching. The Makeup AR approach allows students to learn the knowledge of eyebrows in the system and makeup with the eyebrows displayed on the screen. Students continue to learn by doing and deepen the knowledge learned through hands-on depiction. Employing Makeup AR in makeup education is a new approach, and it exerted a positive effect on teaching in the makeup design certification course. Studies on AR use in educational environments have reported that AR can enrich the learning process $[1,71,76]$. AR technology's effectiveness has been verified in the makeup curriculum area. In the field of makeup design certification, limited research has attempted to apply mobile learning, and thus, examining its role was valuable. Future studies should examine the relationship between mobile learning and makeup design certification.

This study had some limitations that should be addressed. First, it employed a short duration. Future studies should consider increasing the number of experiments to cover a whole semester, for example, and then consider whether the research results are different to verify the stability and generalizability of the experiment results. Second, we suggest applying AR to more cosmetology skills courses in vocational senior high schools. Teaching experiments should be conducted to confirm AR's effect on different courses. Moreover, the sample size for the experiment should be increased, with more students recruited to improve the accuracy of the experiment results. In addition, the choice of equipment may affect the results. In this study's experiment, some students suggested that the Internet speed in the classroom affected the reading of e-books; furthermore, some stated that during the Makeup AR process, holding the smartphone affected their ability to apply makeup. Therefore, in follow-up research, the effects of different systems should be considered. As stated above, many impact factors can be included in AR teaching. Related research points out factors that affect AR learning, such as the learning environment and the intervention duration, which can also be included in future research [69]. In addition, Makeup AR was only used for the eyebrow unit of the course; future studies should explore the use of AR in other units. Related research should continue to develop full-face makeup AR or use technology to teach other certification exam subjects. In addition, technological novelty is a topic worthy of attention. Because unfamiliarity with new technologies may affect students' true thoughts, future research should consider how to overcome this problem. Finally, factors such as different ages, personalities, grades, and genders can be included in future studies to expand the scope and depth of the research. Finally, the learning styles discussed in this study are only significant to cognitive load. They are not significant to learning effectiveness, learning motivation, and self-efficacy. Research has confirmed that whether students are active or reflective students, they will not be affected by the students' learning styles under the learning mode of AR or the e-book. It can be boldly deduced that students' learning styles can be considered excluded from the teaching of makeup in the future.

Author Contributions: Conceptualization, Y.H.; methodology, Y.H.; formal analysis, Y.H.; investigation, Y.H.; resources, Y.H.; data curation, Y.H.; writing—original draft preparation, C.-J.L.; writingreview and editing, C.-J.L.; supervision, C.-J.L. All authors have read and agreed to the published version of the manuscript. 
Funding: This research received no external funding.

Institutional Review Board Statement: Not applicable for this study cos not involving humans or animals.

Informed Consent Statement: Informed consent was obtained from all subjects involved in the study.

Conflicts of Interest: The authors declare no conflict of interest.

\section{References}

1. Bacca, J.; Baldiris, S.; Fabregat, R.; Graf, S. Augmented reality trends in education: A systematic review of research and applications. J. Educ. Technol. Soc. 2014, 17, 133-149.

2. Shih, J.-L.; Chuang, C.-W.; Hwang, G.-J. An inquiry-based mobile learning approach to enhancing social science learning effectiveness. J. Educ. Technol. Soc. 2010, 13, 50-62.

3. Anshari, M.; Almunawar, M.N.; Shahrill, M.; Wicaksono, D.K.; Huda, M. Smartphones usage in the classrooms: Learning aid or interference? Educ. Inf. Technol. 2017, 22, 3063-3079. [CrossRef]

4. Dukic, Z.; Chiu, D.K.; Lo, P. How useful are smartphones for learning? Perceptions and practices of library and information science students from Hong Kong and Japan. Libr. Hi Tech 2015, 33, 545-561. [CrossRef]

5. Bligh, D.A. What's the Use of Lectures? Intellect Books: Bristol, UK, 1998.

6. Ramsden, P. Learning to Teach in Higher Education; Routledge: London, UK, 2003.

7. Kember, D.; Kwan, K.-P. Lecturers' approaches to teaching and their relationship to conceptions of good teaching. Instr. Sci. 2000, 28, 469-490. [CrossRef]

8. Pachler, N.; Evans, M.; Redondo, A.; Fisher, L. Learning to Teach Foreign Languages in the Secondary School: A Companion to School Experience; Routledge: London, UK, 2013.

9. Kennewell, S.; Parkinson, J.; Tanner, H. Learning to Teach Ict in The Secondary School: A Companion to School Experience; Routledge: London, UK, 2003.

10. Norris, L. Learning to teach using ict in the secondary school. A companion to school experience. J. Interact. Media Educ. 2015, 2015. [CrossRef]

11. Panjaburee, P.; Hwang, G.-J.; Triampo, W.; Shih, B.-Y. A multi-expert approach for developing testing and diagnostic systems based on the concept-effect model. Comput. Educ. 2010, 55, 527-540. [CrossRef]

12. Soltani, P.; Morice, A.H.P. Augmented reality tools for sports education and training. Comput. Educ. 2020, 155, 103923. [CrossRef]

13. Dunleavy, M.; Dede, C.; Mitchell, R. Affordances and limitations of immersive participatory augmented reality simulations for teaching and learning. J. Sci. Educ. Technol. 2009, 18, 7-22. [CrossRef]

14. Godwin-Jones, R. Augmented reality and language learning: From annotated vocabulary to place-based mobile games. Lang. Learn. Technol. 2016, 20, 9-19.

15. Ávalos-Ramos, M.; Martínez-Ruiz, M.; Merma-Molina, G. Missing opportunities for gymnastics learning: Voices of secondary education physical education teachers. Ágora Para La Educ. Física Y El Deporte 2015, 17, 130-147.

16. Elfeky, A.I.M.; Elbyaly, M.Y.H. Developing skills of fashion design by augmented reality technology in higher education. Interact. Learn. Environ. 2021, 29, 17-32. [CrossRef]

17. Chang, C.-Y.; Lai, C.-L.; Hwang, G.-J. Trends and research issues of mobile learning studies in nursing education: A review of academic publications from 1971 to 2016. Comput. Educ. 2018, 116, 28-48. [CrossRef]

18. Lonergan, A.R.; Bussey, K.; Mond, J.; Brown, O.; Griffiths, S.; Murray, S.B.; Mitchison, D. Me, my selfie, and i: The relationship between editing and posting selfies and body dissatisfaction in men and women. Body Image 2019, 28, 39-43. [CrossRef] [PubMed]

19. Ng, W.; Nicholas, H. A framework for sustainable mobile learning in schools. Br. J. Educ. Technol. 2013, 44, 695-715. [CrossRef]

20. So, H.-J.; Seow, P.; Looi, C.K. Location matters: Leveraging knowledge building with mobile devices and web 2.0 technology. Interact. Learn. Environ. 2009, 17, 367-382. [CrossRef]

21. Radu, I.; Antle, A. Embodied Learning Mechanics and Their Relationship to Usability of Handheld Augmented Reality. In Proceedings of the 2017 IEEE Virtual Reality Workshop on K-12 Embodied Learning through Virtual \& Augmented Reality (KELVAR), Los Angeles, CA, USA, 19 March 2017; IEEE: Piscataway, NJ, USA; pp. 1-5.

22. Yip, J.; Wong, S.-H.; Yick, K.-L.; Chan, K.; Wong, K.-H. Improving quality of teaching and learning in classes by using augmented reality video. Comput. Educ. 2019, 128, 88-101. [CrossRef]

23. Hsia, L.-H.; Sung, H.-Y. Effects of a mobile technology-supported peer assessment approach on students' learning motivation and perceptions in a college flipped dance class. Int. J. Mob. Learn. Organ. 2020, 14, 99-113. [CrossRef]

24. Lin, Y.-N.; Hsia, L.-H.; Sung, M.-Y.; Hwang, G.-H. Effects of integrating mobile technology-assisted peer assessment into flipped learning on students' dance skills and self-efficacy. Interact. Learn. Environ. 2018, 27, 995-1010. [CrossRef]

25. Baek, Y.; Touati, A. Exploring how individual traits influence enjoyment in a mobile learning game. Comput. Hum. Behav. 2017, 69, 347-357. [CrossRef]

26. Franklin, R.; Smith, J. Practical assessment on the run-ipads as an effective mobile and paperless tool in physical education and teaching. Res. Learn. Technol. 2015, 23. [CrossRef] 
27. Huang, C.-L.; Huang, Y.-M. Facial expression recognition using model-based feature extraction and action parameters classification. J. Vis. Commun. Image Represent. 1997, 8, 278-290. [CrossRef]

28. Dong, Y.; Woodard, D.L. Eyebrow shape-based features for biometric recognition and gender classification: A feasibility study. In Proceedings of the 2011 International Joint Conference on Biometrics (IJCB), Washington, DC, USA, 11-13 October 2011; pp. 1-8.

29. Reilly, M.J.; Tomsic, J.A.; Fernandez, S.J.; Davison, S.P. Effect of facial rejuvenation surgery on perceived attractiveness, femininity, and personality. JAMA Facial Plast. Surg. 2015, 17, 202-207. [CrossRef] [PubMed]

30. Sclafani, A.P.; Jung, M. Desired position, shape, and dynamic range of the normal adult eyebrow. Arch. Facial Plast. Surg. 2010, 12, 123-127. [CrossRef] [PubMed]

31. Cash, T.F.; Dawson, K.; Davis, P.; Bowen, M.; Galumbeck, C. Effects of cosmetics use on the physical attractiveness and body image of american college women. J. Soc. Psychol. 1989, 129, 349-355. [CrossRef]

32. Russell, R. A sex difference in facial contrast and its exaggeration by cosmetics. Perception 2009, 38, 1211-1219. [CrossRef] [PubMed]

33. Wen, L.; Guo, G. Dual attributes for face verification robust to facial cosmetics. J. Comput. Vis. Image Process 2013, 3, 63-73.

34. Sadr, J.; Jarudi, I.; Sinha, P. The role of eyebrows in face recognition. Perception 2003, 32, 285-293. [CrossRef] [PubMed]

35. Alex, J.C. Aesthetic considerations in the elevation of the eyebrow. Facial Plast. Surg. 2004, 20, 193-198. [CrossRef]

36. Sedgh, J. The aesthetics of the upper face and brow: Male and female differences. Facial Plast. Surg. 2018, 34, 114-118. [CrossRef]

37. Jones, A.L.; Porcheron, A.; Russell, R. Makeup changes the apparent size of facial features. Psychol. Aesthet. Creat. Arts 2018, 12, 359. [CrossRef]

38. Azuma, R.T. A survey of augmented reality. Teleoperators Virtual Environ. 1997, 6, 355-385. [CrossRef]

39. Milgram, P.; Kishino, F. A taxonomy of mixed reality visual displays. IEICE Trans. Inf. Syst. 1994, 77, 1321-1329.

40. Goodyear, P.; Retalis, S. Technology-Enhanced Learning; Sense Publishers: Rotterdam, The Netherlands, 2010.

41. Di Serio, Á.; Ibáñez, M.B.; Kloos, C.D. Impact of an augmented reality system on students' motivation for a visual art course. Comput. Educ. 2013, 68, 586-596. [CrossRef]

42. Akçayır, M.; Akçayır, G. Advantages and challenges associated with augmented reality for education: A systematic review of the literature. Educ. Res. Rev. 2017, 20,1-11. [CrossRef]

43. Ibanez, M.; Kloos, C.D.; Leony, D.; Rueda, J.J.G.; Maroto, D. Learning a foreign language in a mixed-reality environment. IEEE Internet Comput. 2011, 15, 44-47. [CrossRef]

44. Yang, J.C.; Chen, C.H.; Jeng, M.C. Integrating video-capture virtual reality technology into a physically interactive learning environment for english learning. Comput. Educ. 2010, 55, 1346-1356. [CrossRef]

45. Dunn, T.J.; Kennedy, M. Technology enhanced learning in higher education; motivations, engagement and academic achievement. Comput. Educ. 2019, 137, 104-113. [CrossRef]

46. Lu, S.-J.; Liu, Y.-C.; Chen, P.-J.; Hsieh, M.-R. Evaluation of ar embedded physical puzzle game on students' learning achievement and motivation on elementary natural science. Interact. Learn. Environ. 2020, 28, 451-463. [CrossRef]

47. Wei, X.; Weng, D.; Liu, Y.; Wang, Y. Teaching based on augmented reality for a technical creative design course. Comput. Educ. 2015, 81, 221-234. [CrossRef]

48. Gecu-Parmaksiz, Z.; Delialioğlu, Ö. The effect of augmented reality activities on improving preschool children's spatial skills. Interact. Learn. Environ. 2018, 28, 876-889. [CrossRef]

49. Ibáñez, M.B.; Di Serio, Á.; Villarán, D.; Kloos, C.D. Experimenting with electromagnetism using augmented reality: Impact on flow student experience and educational effectiveness. Comput. Educ. 2014, 71, 1-13. [CrossRef]

50. Jyoti, V.; Lahiri, U. Virtual reality based joint attention task platform for children with autism. IEEE Trans. Learn. Technol. 2019, 13, 198-210. [CrossRef]

51. Alcaniz, M.; Perez-Lopez, D.C.; Contero, M.; Ortega, M. Augmented Reality Technology for Education; INTECH Open Access Publisher: London, UK, 2010.

52. Bolliger, D.U.; Supanakorn, S. Learning styles and student perceptions of the use of interactive online tutorials. Br. J. Educ. Technol. 2011, 42, 470-481. [CrossRef]

53. Chen, C.-H. An adaptive scaffolding e-learning system for middle school students' physics learning. Australas. J. Educ. Technol. 2014, 30. [CrossRef]

54. Chu, H.-C.; Hwang, G.-J.; Tsai, C.-C.; Tseng, J.C. A two-tier test approach to developing location-aware mobile learning systems for natural science courses. Comput. Educ. 2010, 55, 1618-1627. [CrossRef]

55. Felder, R.M.; Silverman, L.K. Learning and teaching styles in engineering education. Eng. Educ. 1988, 78, 674-681.

56. Filippidis, S.K.; Tsoukalas, I.A. On the use of adaptive instructional images based on the sequential-global dimension of the felder-silverman learning style theory. Interact. Learn. Environ. 2009, 17, 135-150. [CrossRef]

57. Hwang, G.-J.; Sung, H.-Y.; Hung, C.-M.; Huang, I. A learning style perspective to investigate the necessity of developing adaptive learning systems. J. Educ. Technol. Soc. 2013, 16, 188-197.

58. Klašnja-Milićević, A.; Vesin, B.; Ivanović, M.; Budimac, Z. E-learning personalization based on hybrid recommendation strategy and learning style identification. Comput. Educ. 2011, 56, 885-899. [CrossRef]

59. Hawk, T.F.; Shah, A.J. Using learning style instruments to enhance student learning. Decis. Sci. J. Innov. Educ. 2007, 5, 1-19. [CrossRef] 
60. Schunk, D.H.; Zimmerman, B.J. Influencing children's self-efficacy and self-regulation of reading and writing through modeling. Read. Writ. Q. 2007, 23, 7-25. [CrossRef]

61. Eastin, M.S.; LaRose, R. Internet self-efficacy and the psychology of the digital divide. J. Comput.-Mediat. Commun. 2000, 6, JCMC611. [CrossRef]

62. Bandura, A.; McClelland, D.C. Social Learning Theory; Englewood cliffs Prentice Hall: Hoboken, NJ, USA, $1977 ;$ Volume 1.

63. Sweller, J.; Van Merrienboer, J.J.; Paas, F.G. Cognitive architecture and instructional design. Educ. Psychol. Rev. 1998, 10, 251-296. [CrossRef]

64. Wilson, R.K.; Eckel, C.C. Judging a book by its cover: Beauty and expectations in the trust game. Political Res. Q. 2006, 59, 189-202. [CrossRef]

65. Wang, S.-L.; Hwang, G.-J. The role of collective efficacy, cognitive quality, and task cohesion in computer-supported collaborative learning (cscl). Comput. Educ. 2012, 58, 679-687. [CrossRef]

66. Hwang, G.-J.; Yang, L.-H.; Wang, S.-Y. A concept map-embedded educational computer game for improving students' learning performance in natural science courses. Comput. Educ. 2013, 69, 121-130. [CrossRef]

67. Chen, C.-H.; Chou, Y.-Y.; Huang, C.-Y. An augmented-reality-based concept map to support mobile learning for science. Asia-Pac. Educ. Res. 2016, 25, 567-578. [CrossRef]

68. Tseng, J.C.; Chu, H.-C.; Hwang, G.-J.; Tsai, C.-C. Development of an adaptive learning system with two sources of personalization information. Comput. Educ. 2008, 51, 776-786. [CrossRef]

69. Garzón, J.; Baldiris, S.; Gutiérrez, J.; Pavón, J. How do pedagogical approaches affect the impact of augmented reality on education? A meta-analysis and research synthesis. Educ. Res. Rev. 2020, 31, 100334. [CrossRef]

70. Garzón, J.; Acevedo, J. Meta-analysis of the impact of augmented reality on students' learning gains. Educ. Res. Rev. 2019, 27, 244-260. [CrossRef]

71. Garzón, J.; Pavón, J.; Baldiris, S. Systematic review and meta-analysis of augmented reality in educational settings. Virtual Real. 2019, 23, 447-459. [CrossRef]

72. Cai, S.; Liu, E.; Yang, Y.; Liang, J.-C. Tablet-based ar technology: Impacts on students' conceptions and approaches to learning mathematics according to their self-efficacy. Br. J. Educ. Technol. 2019, 50, 248-263. [CrossRef]

73. Salen, K.; Tekinbaş, K.S.; Zimmerman, E. Rules of Play: Game Design Fundamentals; MIT Press: Cambridge, MA, USA, 2004.

74. Huang, H.L.; Hwang, G.J.; Chang, C.Y. Learning to be a writer: A spherical video-based virtual reality approach to supporting descriptive article writing in high school chinese courses. Br. J. Educ. Technol. 2020, 51, 1386-1405. [CrossRef]

75. Yang, G.; Chen, Y.T.; Zheng, X.L.; Hwang, G.J. From experiencing to expressing: A virtual reality approach to facilitating pupils' descriptive paper writing performance and learning behavior engagement. Br. J. Educ. Technol. 2021, 52, 807-823. [CrossRef]

76. Chen, P.; Liu, X.; Cheng, W.; Huang, R. A review of using augmented reality in education from 2011 to 2016 . In Innovations in Smart Learning; Springer: Berlin/Heidelberg, Germany, 2017; pp. 13-18. 